\title{
Os fragmentos da vida de $K$.
}

\author{
The fragments of K's life
}

\section{Natália Brandalise Pinto e Paulo Fernando Monteiro Ferraz ${ }^{2}$}

Resumo: $O$ presente escrito foi articulado a partir de uma experiência clínica vivenciada durante o período de estágio curricular de Psicologia, a partir do atendimento de um paciente adulto bastante regressivo. Tendo em vista a necessária preservação da identidade dos envolvidos no caso retratado, o paciente será chamado de $\mathrm{K}$ e a terapeuta que $\mathrm{O}$ atendia, de Laura. Os fragmentos colhidos da vida de $K$. ., associados a elementos ficcionais, deram origem a uma narrativa que evoca as múltiplas facetas da transferência. Sob um prisma psicanalítico, o estudo traz reflexões acerca das particularidades de um sujeito cuja parte psicótica se destaca nas sessões. No decorrer dos atendimentos e na presença da terapeuta, houve a tentativa de inscrever em K. um universo mais aproximado do princípio da realidade. Portanto, busca-se, de forma condensada, frisar os aspectos mais relevantes do caso, possibilitando desta maneira, a reflexão e compreensão acerca dos fenômenos que ocorriam no setting.

Palavras-chave: Psicanálise; Psicose; Transferência.

\begin{abstract}
The present paper was articulated through clinical experience obtained during the Psychology period of curricular internship, from the treatment of a particularly regressive adult patient. In view of the necessary identity preservation of those involved in the depicted case, the patient will be called $\mathrm{K}$, and the therapist who treated him will be called Laura. The fragments collected from K's life, associated with fictional elements, gave origin to a narrative that evokes the multiple facets of transference. Under a psychoanalytic framework, the study reflects on the particularities of an individual whose psychotic part stands out in the sessions. During the sessions and in the presence of the therapist, there was an attempt of subscribing within $\mathrm{K}$ a universe more closely related to the principle of reality. Therefore, in a condensed way, there was an attempt to emphasize the most relevant aspects of the case and make it possible to reflect and comprehend the phenomena that occurred in the setting.
\end{abstract}

Keywords:Psychoanalysis; Psychosis; Transfer.

\footnotetext{
1 Graduanda do curso de Psicologia da Pontifícia Universidade Católica (PUCRS). Sócia SPRGS. Integrante da Oficina de produção psicanalítica e literária (SPRGS). E-mail: natalia.brandalise@edu.pucrs.com.br

2 Psicanalista (CEPdePA). Mestre em Psicologia Social e Institucional (UFRGS). Coordenador da Oficina de produção psicanalítica e literária (SPRGS).E-mail: paulovortex@yahoo.com.br
} 


\section{Introdução}

Esta escrita é um convite à flutuação em torno de uma experiência clínica. Pretende-se compartilhar alguns episódios da vida de K. Há sempre elaborações ficcionais acerca de um paciente. $0 \mathrm{~K}$. que será apresentado possui camadas de imaginação aliadas à transferência. Eis aí um modo de manter 0 sigilo. Nasio afirma que: "Em psicanálise, definimos o caso como o relato de uma experiência singular, escrito por um terapeuta para atestar seu encontro com um paciente e respaldar um avanço teórico" (Nasio, 2001, p. 11).

Ao desenvolver o caso, foi possível refletir e construir hipóteses acerca dos fenômenos que ocorriam no setting, que conforme Ferraz:

0 Setting, esse espaço de sonhos e de criação de destinos mais generosos aos conflitos, é o lugar em que o estranho tende a retomar à pátria, o desgarrado a encontrar o empuxo da alteridade e 0 inominado a se alfabetizar acerca do idioma de sua cor (Ferraz, 2020, p. 166).

No decorrer dos atendimentos e a partir da presença de Laura, a terapeuta, o paciente foi capaz de deixar emergir partes ainda não nascidas de sua personalidade, ilustrar as histórias, mitos pessoais e deixar vir à tona a criança que o habitava - talvez arrancada de uma infância turbulenta e que implorava por ser olhada. Houve a tentativa de inscrever em K. um universo mais aproximado do princípio da realidade.

\section{O primeiro encontro}

No dia em que Laura conheceu K, deparou-se com um homem de 28 anos que, aos poucos, começou a trazer à baila a criança escondida em si. Ela o cumprimentou e percebeu que andariam por geografias insólitas e, antes mesmo de se sentar, uma sensação indefinível de alheamento infiltrou-se em seus poros e fez com que se parecesse menos humana. Era um mal-estar que antecipava o papel que assumiria ali, naquele teatro transferencial.

Em seguida, K. pediu para desenhar. A solicitação surpreendeu Laura, mas ela Ihe entregou o material de desenho. Os olhos verdes do paciente fitavam intensamente a folha em branco. Aos poucos, os traços foram dando vida a um alienígena. K. começou a compartilhar inúmeros personagens que o povoavam: os planetas, os alienígenas, as naves espaciais e todos os aparatos que aludiam a algo interplanetário. Tudo isso transportava Laura para as camadas de seu mundo interno. Vale lembrar a afirmação de Ogden (2010): "é responsabilidade do analista reinventar a psicanálise para cada paciente e continuar a reinventá-la durante o curso da análise" (p. 22).

\section{Os alienígenas}

K. carregou Laura para os seus 10 anos de idade. Estava dentro da van escolar em companhia do motorista e dos colegas. Dirigiam-se à escola. Em meio a isso, K. contemplava o céu. Então, testemunhou uma nave espacial, que acompanhava o veículo durante todo o trajeto. A cena narrada armava uma atmosfera de suspense, como nos filmes de terror. 0 paciente prosseguiu com muita convicção: "0 motorista precisava acelerar, quase que cegamente, para superar qualquer obstáculo que pudesse atrapalhar o caminho" (K.,
Comunicação pessoal). Tal comentário deu a entender, que todos os presentes perceberam algo estranho. Mais tarde, após terem chegado ao destino, 0 assunto não foi mais abordado. Intimamente, os colegas, sabiam que se tratava de uma alucinação e mantiveram isso em sigilo. Tal segredo seria uma sentença na vida de $\mathrm{K}$ ?

Diante de sua terapeuta, o paciente a convidava a migrar para o seu universo alienígena. Com ele, Laura tornou-se a terráquea em contato com a linguagem estrangeira de seu inconsciente.

\section{Os vômitos}

K. contou que, após o primeiro contato com os seres alienígenas, passou a vomitar todos os dias, durante muito tempo. Pode-se pensar que expelia os conteúdos do estômago e, com isso, eliminava todos os resíduos das partes más, os perseguidores que o amedrontavam. Seja no sentido concreto ou simbólico, havia algo em seu interior que o repugnava e que necessitava ser violentamente lançado para fora de si. Caso contrário, seria intoxicado por todos esses conteúdos terroríficos e destrutivos. Ogden (2010) complementa a ideia:

Os elementos-beta - impressões sensoriais não processadas não podem ser ligados entre si e, consequentemente, não podem ser utilizados para pensar, sonhar ou armazenar memória. Em contraste, os elementos-alfa são elementos da experiência que podem ser ligados entre si no processo consciente e inconsciente de pensar e de sonhar (pp. 18-19).

Pensando nos conceitos de Bion, os conteúdos destrutivos são os elementos-beta, impressões sensoriais não processadas e que não podem ser ligadas entre si e que, consequentemente, K. tentava evacuar.

\section{As perseguições}

Afora os alienígenas, outros terrores 0 espreitavam. Desde a época em que seu pai estava vivo, K. notava que havia hostilidades, conflitos e desavenças. 0 pai era tachado de demônio pelos demais. Em momentos de tumultos, K. também recebia a alcunha de demônio. K. pertencia à mesma linhagem do pai. Talvez, na família, a masculinidade e a virilidade tivessem um quê de anômalo. A mãe de K. por algum motivo, tendia a escolher parceiros violentos e abusivos. Quando as brigas começavam, K. corria para o porão da casa, lugar que tornou-se seu esconderijo.

No setting, Laura imaginou-se como uma criança que fugia de algo obscuro. Talvez K. pudesse ter sentido o mesmo. Sobre o fenômeno da transferência que ali se instalava, Ferro (2011) ressalta:"a transferência, neste sentido, é também o transferir das capacidades do analista para o campo e do campo para o paciente, que, por sua vez, traz o combustível e seus instrumentos para o processo" (p. 21). Assim, K. puxou-a pelo braço e fez com que se transportasse à infância e a todos os assombros e perplexidades que compunham essa temporalidade. 


\section{Os silêncios}

Fora do setting, K. era invadido por vozes - as internas e as externas. Os julgamentos estavam por toda parte. Inflado pela onipotência, o mundo se voltava para cada passo seu. A paranoia não dava trégua. No entanto, 0 silêncio partilhado durante a sessão não 0 atordoava e, sim, possibilitava que os pensamentos emergissem de suas profundezas. Esse silêncio irradiava ares de intimidade que convocavam Laura a assumir uma postura de maternagem, em que nomeava e traduzia, em ritmos variados, as aflições de K. Tal como destaca Nasio (2010): "0 silêncio está sempre presente numa sessão de análise, e seus efeitos são tão decisivos quanto os de uma palavra efetivamente pronunciada" (p. 7).

Nessa entrega, as emoções estrangeiras tinham abrigo temporário. 0 psiquismo dela era o continente das partes nebulosas que levavam K. para outras dimensões de sua personalidade. Era um lugar seguro. Em sua presença, podia largar os óculos escuros e tudo o que fazia parte de seu disfarce. Ele os usava para não ser reconhecido mundo afora. Sofreu várias violências e queria impedi-las. Os óculos escuros se converteram em talismãs. Acabavam protegendo $K$. de algo ameaçador que ele acreditava com veemência estar do lado de fora, quando, na verdade, vinha de suas entranhas.

\section{Os sonhos}

Certa manhã, Laura despertou de um sonho intrincado e complexo. Vagarosamente, foi desvendando e lembrando dos detalhes. No sonho, havia um alienígena na Terra. Militares e policiais estavam por toda parte e procuravam por esse ser estranho que havia invadido nosso planeta. Por algum motivo, ela era a única que sabia onde encontrá-lo. Apesar da pressão por parte dos policiais para que ela revelasse seu esconderijo, recusava-se a dar qualquer informação. Seu silêncio representava lealdade. 0 tom de voz autoritário dos policiais the causava calafrios. Não conseguiu saber se encontraram ou não 0 alienígena.

Durante o resto do dia, o sonho se reavivou em seus pensamentos. Seria K. o alienígena no qual ela tentava proteger durante o sonho? Deu-se conta do efeito que a sessão anterior havia surtido. Era como se o paciente houvesse plantado sementinhas que, depois, despertariam. Algo dele Ihe acompanhava e, talvez, somente assim K. fosse capaz de enfrentar todos os pesadelos que o maceravam.

Queria dividir com Laura toda sua angústia, tanto que ela o sonhou. K. Ihe transformou em guardiã de sua parte lúcida, saudável e fincada na realidade. Épossível supor que K. não tenha tido espaço no psiquismo da mãe e, provavelmente, nem no do pai. Nesse sentido, Ogden amplia:"Ao participar do sonhar os sonhos não sonhados e interrompidos do paciente, o analista não está simplesmente vindo a conhecer o paciente; ele e o paciente estão juntos vivendo a experiência emocional até então insonhável ou ainda-a-ser-sonhada na transferência-contratransferência" (Ogden, 2010, p. 25).

\section{O pai}

K. contou que seu pai havia sido enterrado como indigente. 0 medo da história se repetir com ele o perturbava constantemente. Indigente traz a signo dramático de algo sem nome, sem lugar e sem origem, assim como ele se sentia. Essa marca de indigência alude aos conteúdos psíquicos sem continente. Por essa razão, K. buscava um lugar de pertencimento, uma terra para firmar os pés na realidade.

K. relembrava episódios tensos da infância e, muitas vezes, Laura jogava mais combustível às lembranças obscuras dessa época da vida de K. e ele Ihe contava:

As brigas eram constantes na família. 0 meu pai bebia todas as noites e espancava a minha mãe. Eu vivia em meio àquela constante violência doméstica. Nem eu e nem os meus irmãos entendíamos o que acontecia, mas algum critério dentro de mim me fez agir: em uma das ocasiões, enquanto ele esbofeteava o rosto de minha mãe, eu peguei uma faca na cozinha e o ameacei. Com um solavanco, fui jogado contra a parede. Não sei o que houve. Só há um blecaute nesse trecho da memória. Algo me desligou. Que final dar a isso, eu não sei (K. Comunicação pessoal).

Eis aí os emblemas da hostilidade e das loucuras privadas da família. Mesmo com a morte do pai, o lastro de violência ainda habita a casa e 0 íntimo de cada um deles.

\section{A letra K.}

K. fazia com Laura expedições galácticas, visitava outros planetas dentro de si, orbitava em torno dos wormholes e dos buracos negros, mas sabia que ela possuía o passaporte para o reingresso na Terra, para o mundo cotidiano. Ele a escolheu para que fosse, por enquanto, o elo que o manteria, em certa medida, com os pés no chão. Em seus encontros, essa membrana fronteiriça entre a neurose e a psicose ganhava novos contornos e algumas permeabilidades. Era como se, com as palavras, criassem alfândegas que pudessem revistar e filtrar os conteúdos psíquicos e, por conseguinte, situá-los em suas respectivas cidadanias. Como destaca Dametto (2013) "o terapeuta do psicótico deve ser o consciente do paciente, diferente do terapeuta do neurótico, que deve ser 0 representante do inconsciente do mesmo" (p. 19).

Não foi à toa que a letra K tenha sido elegida como o invólucro de sua identidade. Talvez tenha sido no dever de, assim como ele, ocultar detalhes mais reveladores. Pode-se pensar que K. viesse a significar a parte ainda não alfabetizada de suas relações e que, aos poucos, as vogais e consoantes de seu psiquismo pudessem se sofisticar e formar palavras e frases dotadas de mais sentido.

\section{As vozes de $K$.}

Assim como Schreber, K. atraía para si um ar de grandeza. Acreditava ter um poder extraordinário que o permitia se comunicar com alienígenas. Mais do que isso, ele era o eleito na Terra para estabelecer essas trocas intergalácticas. Lacan destaca: "0 que caracteriza um sujeito normal é precisamente não levar jamais a sério um certo número de realidades cujas existências ele reconhece" (Lacan, 1956[1955]-1985, p. 90). Ao contrário da definição de sujeito normal proposta pelo autor, K. não tinha dúvidas de que os extraterrestres sabiam seu nome ao chegarem aqui. As certezas precisavam ser esburacadas, furadas. 


\section{As linhas}

Em uma das sessões em que K. chegou sentindo-se bastante angustiado e as palavras não davam conta de explicar os sentimentos, decidiu tentar se expressar através de um desenho. 0 desenho era composto por duas linhas, uma senoide e uma espécie de eletrocardiograma. Enquanto desenhava, Laura lembrou-se dos primeiros encontros com K. e do início do vínculo. Ao fazer as linhas, orientou-a que a senoide significava um equilíbrio já alcançado em outros tempos e o eletrocardiograma remetia às turbulências que passara na vida.

Assim como a Escala Richter, capaz de medir a magnitude dos terremotos com base nas ondas sísmicas que se propagam a partir do local de origem do tremor no subsolo, os rabiscos de K. identificavam possíveis tsunamis e atividades vulcânicas emocionais, capazes de causar grandes desabamentos e estragos na qualidade dos vínculos estabelecidos com as realidades internas e externas.

Preocupado, perguntou à Laura se corria o risco de, enquanto estivesse na linha turbulenta, sofrer um "desequilíbrio mental" - como atribuía seu estado de ânimo. Ela imaginou que o "desequilíbrio mental"poderia significar um surto psicótico e, consequentemente, uma nova internação. Sem que precisassem mencionar, o temor ficou entre eles. Eis as oscilações das posições esquizo-paranóides e depressivas.

\section{0 afastamento}

Ao chegar na sessão, K. anunciou, bastante contrariado, que sua mãe havia pedido que a frequência das sessões diminuísse. Segundo ela, K. perdia muito tempo com o deslocamento até a clínica, sem contar que os honorários pesavam no orçamento.

K. disse que sofreria com a redução dos encontros, pois ali era o único lugar onde sentia-se capaz de ter uma "conversa de verdade", mas que seria impossível dissuadi-la. Nesse momento, Laura percebeu que não teria a menor chance de competir contra o desejo de sua mãe. Era como se houvesse um pacto entre os dois, no qual ela não fazia parte. Combinaram que, por enquanto, os encontros passariam a se dar apenas duas vezes na semana.

Ao final da sessão, K. perguntou se o seu terceiro horário continuaria vago, caso conseguisse convencer a mãe a manter a frequência de três vezes semanais. Laura respondeu que sim. Era verdade, queria acreditar que essa decisão seria temporária. Lembrou da linha que K. havia desenhado em uma das sessões anteriores e a imaginou se rompendo. Ao se despedirem, sem que houvesse a necessidade de ser dito, notou que havia algo de cúmplice em seus olhares. Passou o resto do dia lidando com as indagações que ressoavam em sua cabeça. Havia falhado? Onde? Ou seria, quem sabe, um ataque de sua mãe na tentativa de destruir um terceiro, no caso Laura, que entrava em suas vidas?

É uma hipótese pensar a união de K. e a de sua mãe como simbiótica: ambos permanecem em um estado de total dependência, tal como o bebêno útero. Ao entrar nesse terreno, a presença de Laura tornou-se ameaçadora, pois, de repente, K. passou a reivindicar mais autonomia, na tentativa de se desfazer da toxicidade do vínculo materno. Sem que a mãe estivesse preparada para tal ruptura, percebeu as mudanças do filho como atos de rebeldia. A partir disso, buscou uma maneira de interferir no tratamento e diminuir a intensidade de seus efeitos, temendo perder "seu eterno menino".

\section{As perguntas}

Sem rodeios, K. perguntava o que deveria fazer para levar uma vida mais próxima da normalidade. Seu olhar implorava por uma solução, como se Laura guardasse a fórmula mágica capaz de dissipar todos os problemas que 0 atormentavam. Depois de se dar conta de que ela não possuía a resposta e perceber que, assim como ele, tinha seus próprios defeitos, aborrecia-se e reivindicava: "Tu deverias me dizer o que fazer" (K., Comunicação pessoal). Mesmo chateado, sabia que ainda poderia dividir as angústias de tantas dúvidas. Talvez aí ele a tenha colocado, na transferência, como uma pessoa disponível, mundana, oposta às expectativas celestiais e extraterrenas que atribuía aos demais. Parece que 0 gérmen da alteridade começava a dar as caras.

Em outras sessões, demonstrava desejo pelos estudos sobre células, moléculas e DNA. Com isso, K. dava vazão à curiosidade em relação ao próprio corpo e as diferenças anatômicas entre um sujeito e outro. É claro que, além disso, ambicionava construir, com o olhar de Laura associado ao dele, um corpo psíquico, humano, pulsante em ontologia.

\section{O futuro de $K$.}

Algum tempo depois que já haviam diminuído a frequência das sessões, K. chegou com um aspecto incomum e contrastante: cabelos compridos e desgrenhados, olhos cansados e desolados, mal agasalhado, a despeito do frio que fazia nesse dia. Ao vê-lo, Laura foi tomada por um tremendo mal-estar. Como se captasse suas sensações, foi logo explicando que as coisas em casa não andavam bem. Com o dinheiro cada vez mais escasso, muitas vezes, não tinham o que comer. 0 sofrimento estampava-se em seu semblante.

Nessa sessão, não se interessou pelos desenhos, nem pelas revistas, nem trouxe assuntos interessantes que costumava pesquisar na Internet e que sempre contava com muita empolgação. Apenas falou o quanto se encontrava cansado, cansado das pessoas que o perseguiam e o insultavam, cansado do ambiente hostil de sua casa, cansado da "vida miserável" que levava. Laura sentiu-se impotente diante de tantas dificuldades que a vida Ihe impunha.

No fim desse encontro, carregou K. nos pensamentos. 0 que seria dele dali para frente? Por enquanto, conseguia sustentar com ela dois encontros semanais. E quando o seu estágio terminasse? Como ela lidaria com isso? E a vida de K. sem sua presença, como seria? Pelo que já o conhecia, notava muitas limitações em várias instâncias de sua existência. Até aquele momento, K. só havia tido uma experiência de trabalho e não conseguia estabelecer muitos vínculos por aí afora. Sua mãe já era bastante idosa... Que futuro adotaria para si?

Talvez, em companhia dele, Laura pudesse sonhá-lo e fazer um rascunho ou uma concepção de um K. mais liberto da inanição dos objetos bons. Suas palavras tendiam nutri-Io, portavam a qualidade de um leite que o conduzia a horizontes diferentes dos que já testemunhara. 0 olhar que lançava sobre $K$. tinha a cola para unir os fragmentos dispersos que compunham a sua subjetividade. Apostou nisso. Supunha que o setting analítico pudesse simular um útero que promovesse o nascimento do simbolismo. Mesmo que, em algum momento, o percurso tivesse de ser encerrado, acreditava que algo dela ficaria em K. e vice-versa. 


\section{Considerações Finais}

Acredita-se que os fragmentos dessa narrativa sejam frutos de tudo aquilo que K. não foi capaz de simbolizar ou de dramatizar. Durante as sessões, a partir da função continente de Laura, o paciente teve a possibilidade de construir as linhas de ligação em meio a um discurso predominantemente fracionado. Ademais, a escrita tornou-se uma forma de suportar e elaborar essa desintegração. Muito mais do que interpretativo, entende-se esse trabalho como uma artesania da escuta e da construção de significados e significantes.

\section{Referências}

Ogden, T (2010). Esta arte da psicanálise: Sonhando sonhos não sonhados e gritos interrompidos. Porto Alegre: Artmed.

Nasio, J. D. (2001). Os grandes casos de psicose. Rio de Janeiro: Zahar. Nasio, J. D. (2010). O silêncio na psicanálise. Rio de Janeiro: Zahar.

Ferraz, P. (2020). Incursões na vida fantasmática: a transferência. Rev. CEPdePA, 27. Recuperado em: https://cepdepa.com.br/wp-content/ uploads/2020/12/13-Paulo-Fernando-Monteiro-Ferraz-Incursoes-na-vida-fantasmatica-a-transferencia.pdf

Dametto, C. (2013). Psicoterapia do paciente psicótico. Petrópolis: KBR.

Ferro, A. (2011). Evitar as emoçōes, viver as emoçōes. Porto Alegre: Artmed. Lacan, J. (1956[1955]-1985). O seminário, livro 3: As psicoses. Rio de Janeiro: Zahar. 